\title{
EARLY EXPERIENCE WITH DAY CARE STAPLED HAEMORRHOIDECTOMY
}

\author{
Kunda Bikram Shah ${ }^{1}$, Bikash Bahadur Thapa ${ }^{1}$, Santosh Khadka ${ }^{2}$, Srijan Malla ${ }^{1}$, Sushil Bahadur Rawal ${ }^{1}$, Naresh Kumar \\ Giri $^{1}$, Nagendra Bahadur KC ${ }^{2}$, Sashi Rai ${ }^{2}$ \\ ${ }^{1}$ Department of General Surgery, Shree Birendra Hospital \\ ${ }^{2}$ Department of Anesthesiology, Shree Birendra Hospital
}

\begin{abstract}
Introduction: Improvements in anesthesia, pain management, the evolution of minimally invasive surgery and changing attitudes to recovery after surgery have all promoted to the expansion of scope of day care surgery. The use of stapled haemorrhoidectomy is an accepted treatment modality for prolapsing hemorrhoids of varying degree. To evaluate the outcome of patients undergoing stapled hemorrhoidectomy in the early postoperative period with special focus on pain intensity, requirement of analgesic and its feasibility as a day care procedure.
\end{abstract}

Method: Interventional, clinical, hospital based study carried out at Shree Birendra Hospital between November 2010 and May 2011. The feasibility of discharging patients on the day of Stapled Hemorrhoidectomy was evaluated.

Results: Of the eleven $(n=11)$ patients selected for daycare Stapled Hemorrhoidectomy ten patients ( 90\%) could be discharged after six hours of observation.

Conclusion: Stapled Hemorrhoidectomy is a safe and easily mastered technique with superior results in the immediate/ early postoperative period. The initial cost of the stapling device is the main concern but social and economic savings related to a faster recovery may offset the initial cost especially when it is performed on a day care basis.

Key words: daycare, hemorrhoidectomy, staples.

\section{INTRODUCTION}

Improvements in anaesthesia, pain management, the evolution of minimally invasive surgery and changing attitudes to recovery after surgery have all promoted to the expansion of scope of day care surgery. ${ }^{1}$ The use of stapled haemorrhoidectomy (SH) is an accepted treatment modality for prolapsing hemorrhoids of varying degree. Since November 2008 the Department of Surgery, Shree Birendra Hospital has been performing $\mathrm{SH}$ on a regular basis and after the initial gratifying results, we attempted this surgery in an ambulatory setting. This paper aims to review retrospectively the effectiveness and safety of this technique as a day care procedure.

\section{METHOD}

This study was carried out by Department of Surgery and Anaethesiology at Shree Birendra Hospital between November 2010 and May 2011. Eleven patients with varying degrees of prolapsing hemorrdoids were included in the study. Patient with Thrombosed piles, prolapse of one 
anal cushion, associated anal fistulas, recurrence after surgery except banding, unwilling for daycare surgery and patients residing outside the valley were excluded from the study.

Patients were clinically examination, routine pre-operative investigation \& sigmoidoscopy done.

All 11 patients were operated under caudal anesthesia supplemented with i.v. Midazolam. Four patients needed supplementary i.v anesthesia due to inadequate caudal block. The patients were advised to consume only liquids a day prior to surgery. After an overnight fast, enema with a solution of glycerine and sodium chloride (EZIVAC) was given in the morning prior to surgery. Patients were listed as the first case on the day of surgery.

A single dose of a 3rd generation cephalosporin (cefotaxime or ceftriaxone) was administered before anesthesia and patients were advised to continue metronidazole $400 \mathrm{mg}$ three times a day for 7 days and Lactulose was given $15 \mathrm{ml}$ twicw daily for 10 days. For post operative pain management NSAIDS (Paracetamol+ Ibrufen) was prescribed thrice a day for first three days and then as per requirement. NSAIDS were started after three hours of surgery (once patient was fully alert) to prevent breakthrough pain once the regional anaesthetic effect was worn off. The rectal pack was removed after three hours of surgery. Sitz bath was recommended to all patients for at least seven days.

Visual analogue pain score was maintained during the period of observation in the postoperative ward and at first bowel evacuation. All patients with a VAS $>6$ were given opiod analgesic (meperidine + promethazine). Patients were discharged after six hours of surgery once they fulfilled the discharge criteria (General condition fair with a VAS $<4$, Vitals stable, Acceptance of oral feeds and Evacuation of bladder).

At discharge the patients were advised to report to the ER in case of per rectal bleed, excessive breakthrough pain, urinary retention or any other complaints. They were also advised to follow up between the seventh to tenth postoperative days and also encouraged to come at three months, six months and after one year. Those who failed to review were interviewed over the phone.

Surgical technique: SH by Longo's technique (Fig.1) has two broad principles: Precise placement of a purse string at least 3-4 cm above the dentate line with a $2 / 0$ prolene and application of the $33 \mathrm{~mm}$ circular stapler device. It involves circumferential excision of a strip of mucosa and submucosa well above the dentate line. Activation of the gun simultaneously repairs the cut mucosa and submucosa with double row of staples.

\section{RESULTS}

The mean age of the patients was thirty three years. There was a male preponderance of 8:3. Out of the eleven patients, one patient was admitted because of postoperative pain after pack removal (VAS =5). However, he did not need any opoid analgesic and was discharged the following day.

All patients had prolapse of varying degree, seven patients had bleeding per rectum (64\%), five had associated pruritis ani (45\%) and four had discomfort during defaecation (36\%) (Fig 1). Nine patients had third and only two had second degree prolapsed. The mean operating time was $12.5 \mathrm{~min}$. The mean VAS was 2.25 at the time of discharge, 2.8 at first evacuation and 1.8 at 10th postoperative day.

All patients underwent surgery under a caudal block supplmented with i.v Midazolam for light sedation.The success rate was around sixty three percent and the remaining thirty seven percent of patients needed supplementary Intravenous Anesthesia with propofol.

The return to normal activity was at an average of 7.2 days this excluded the routine physical training that soldiers have to undergo in the military barracks.

Just one patient needed a single dose of opiod analgesic and this was one out of the three patients where there was caudal block failure.

There were few postoperative complications; one patient developed thrombosis the very next day that was managed conservatively and resolved by day ten. Another patient developed post defaecation pain after nearly two months of surgery. A per rectum and proctoscopic examination were within normal limits and he responded well to conservative measures. One unique complication that needs mentioning is that of patient who developed chronic constipation in the second week. All investigations including a Barium Enema were within normal limits. He is on regular follow up and is being managed with laxatives (Table 2).

\begin{tabular}{|l|l|}
\hline \multicolumn{2}{|c|}{ Table - 1: Exclusion criteria for outpatient surgery. } \\
\hline I. & Medical \\
\hline & a. Unfit ASA IV, ASA III \\
\hline & $\begin{array}{l}\text { b. Obese: Body mass index> 35 } \\
\text { major intrathoracic, intraabbominal or intra- } \\
\text { cranial surgery }\end{array}$ \\
\hline d. Procedures requiring more than one hour \\
\hline $\begin{array}{l}\text { e. Surgery expected to have major fluid or } \\
\text { blood loss. }\end{array}$ \\
\hline
\end{tabular}




\begin{tabular}{|l|l|}
\hline II. & Patient \\
\hline & $\begin{array}{l}\text { a. Concept of day care surgery unacceptable to the } \\
\text { patient. }\end{array}$ \\
\hline & b. Psychologically unstable \\
\hline & c. If patient lives far away from the hospital \\
\hline & d. Infants < 3 months of age and preterm babies. \\
\hline III. & Social : No competent relative or friend to \\
\hline & i) Accompany or drive patient home after operation \\
\hline & ii) Look after him or her at home for the next 24-48 hrs. \\
\hline
\end{tabular}

Figure 1. Presenting symptoms of the patients

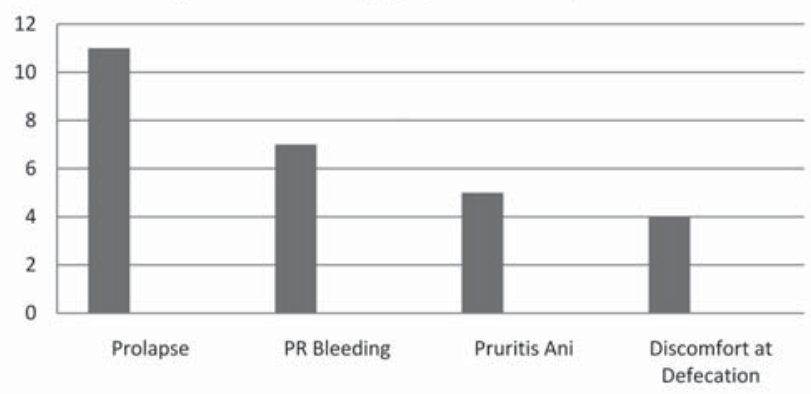

Table: 2 Postoperative Complications

\begin{tabular}{|l|l|}
\hline Complications & No. of cases \\
\hline Painful defecation & 1 \\
\hline Constipation & 1 \\
\hline Anal discharge & 1 \\
\hline Thrombosis & 1 \\
\hline
\end{tabular}

Of the ten patients discharged on the day of surgery none reported the same day in the ER.

\section{DISCUSSION}

Success of day care surgery can be attributed to advances in surgical technologies and in the field of anaesthesiology2. It also involves a thorough patient selection and identifying patients who are unsuitable for medical and social reasons. Although some exclusion criterias have been laid down in literature, most of the patients are amenable for day care surgery (Table 1).2

Hemorrhoids are an ancient disease and its treatment has undergone numerous modifications and innovations down the ages. The Milligan-Morgan technique has stood the test of time in being the most popular procedure for hemorrhoidectomy3. Unfortunately, it has been far from popular among patients 4 because of prolonged postoperative discomfort5.The cause for this extensive pain is due to the result of wide external wounds in the richly innervated perianal skin.
Among the newer surgical options currently available, hemorrhoidectomy performed by use of a circular stapler has not just shown promise but it has come up as a daycare procedure with minimal postoperative pain and early return to work $6,7,8$. The pain is less because the procedure does not involve any surgery below the dentate line. Mean pain scores in various other studies conclusively prove that the postoperative pain is less after stapled technique 5-12.

In this present study out of eleven patients only one patient needed admission due to postoperative pain and ten patients could be sent home. Although the sample size is relatively small to be drawing conclusions the success rate for the procedure was $91 \%$. None of the patients who left hospital on the day of surgery reported to ER for complications. Although there were complications, most were treated during routine follow up and none of the patients needed a second intervention or hospital admission.

Currently, the Singapore General Hospital has the largest series of $\mathrm{SH}$ with over seven thousand three hundred operations 13 and it does so routinely in an ambulatory setting 14,15. A meta-analysis of most randomized controlled trials have clearly shown that $\mathrm{SH}$ is a safe and effective treatment for haemorrhoids that require surgery with far superior short term benefits and acceptable long term results although it had a slightly higher incidence of recurrence.This information needs to be discussed with the patients fairly and ultimately it is the patients choice whether to accept a higher recurrence rate or take advantage of the short term benefits of SH 16.

\section{CONCLUSION}

The main advantage of $\mathrm{SH}$ is that it is a relatively painless procedure and this forms the main basis for carrying out day care surgery.Day care surgery has many benefits to the patient and the hospital. The home environment is more comfortable, there is no restriction of visting hours, long operation waiting list is averted and medical resources are saved.This was also well received by the nursing team in the busy surgical and postoperative wards.

\section{REFERENCES}

1. Russell RCG,Williams NS, Bulstrode CJK. Bailey and Love's short practice of surgery. 24th edn. London: Hodder Arnold; 2004. p.228-38.

2. Wig J. The current status of day care surgery - a review. Indian J. Anaesth. 2005;49(6):459-466.

3. Milligan ETC, Morgan CN, Jones LE, Officer R. Surgical anatomy of the anal canal, and operative treatment of haemorrhoids. Lancet. 1937;2(11): 19-24.

4. Orrom W, Hayashi A, Rusnak C, Kelly J. Initial experience with stapled anoplasty in the operative management of prolapsing hemorrhoids and mucosal rectal prolapse. Am J Surg. 2002;183:519-24.

5. Ortiz H, Marzo J, Armendariz P. Randomized clinical trial of stapled haemorrhoidopexy versus conventional diathermy 
haemorrhoidectomy. Br J Surg. 2002;89:1376-81.

6. Bikhchandani J, Agarwal PN, Kant R, Malik VK. Randomized controlled trial to compare the early and mid results of stapled versus open hemorrhoidectomy. Am J Surg. 2005;189(1):56-60.

7. Ganio E, Altomare DF, Gabrielli F, Milito G, Canuti S. Prospective randomized multicentre trial comparing stapled with open haemorrhoidectomy. Br J Surg. 2001;88:669-74.

8. Pavlidis T, Papaziogas B,Souparis A, et al. Modern stapled Longo procedure vs conventional Milligan-Morgan hemorrhoidectomy: randomized controlled trial. Int J Colorectal Dis. 2002;17:50-3.

9. Shalaby R, Desoky A. Randomized clinical trial of stapled versus Milligan-Morgan haemorrhoidectomy. $\mathrm{Br} J$ Surg. 2001;88:1049-53.

10. Mehigan BJ, Monson JRT, Hartley JE. Stapling procedure for haemorrhoids versus Milligan-Morgan haemorrhoidectomy. Randomized controlled trial. Lancet. 2000;355:782-5.

11. Hetzer FH, Demartines N, Handschin AE, Clavien PA. Stapled vs excision hemorrhoidectomy: Long-term results of a prospective randomized trial. Arch Surg. 2002;137:337-40.

12. Rowsell M, Bello M, Hemingway DM. Circumferential mucosectomy versus conventional haemorrhoidectomy: Randomized controlltrial. Lancet. 2000;355:779-81.

13. Ming-Hian Kam, Kheng-Hong Ng,Jit-Fong Lim,Kok-Sun Ho,Boon-Swee Ooi,Choong-Leong Tang et al. Results of 7302 stapled haemorrhoidectomy operations in a single centre: a seven-year review and follow-up questionnare survey. ANZ J Surg. 2011;81(4):253-6.

14. Ng KH; Ho KS; Ooi BS; Tang CL; Eu KW. Experience of 3711 stapled haemorrhoidectomy operations. $\mathrm{Br}$ J Surg. 2006;93(2):226-30.

15. Guy RJ, Ng CE, Eu KW. Stapled Anoplasty for haemorrhoids; a comparison of ambulatory vs. in-patient procedures. Colorectal Dis. 2003;5:29-32.

16. Giordano P; Gravante G; Sorge R; Ovens L; Nastro P. Longterm outcomes of stapled hemorrhoidopexy vs conventional hemorrhoidectomy: a meta-analysis of randomized controlled trials.Arch Surg. 2009;144(3):266-72.
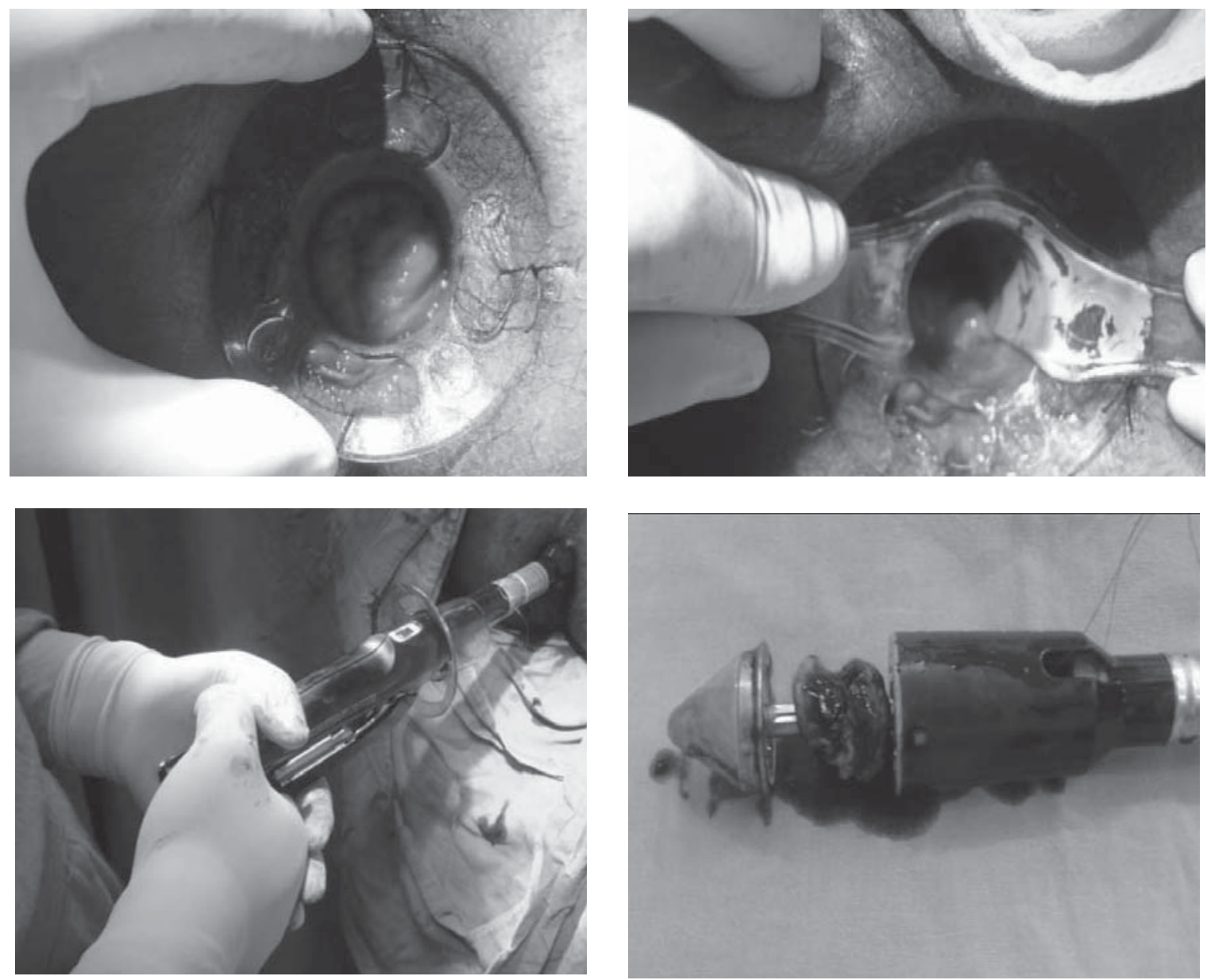

Figure 1(A - D). Steps of surgery 